International Journal of Current Advanced Research

ISSN: O: 2319-6475, ISSN: P: 2319 - 6505, Impact Factor: SJIF: 5.995

Available Online at www.journalijcar.org

Volume 6; Issue 3; March 2017; Page No. 2856-2858

DOI: http://dx.doi.org/10.24327/ijcar.2017.2858.0124

Research Article

\title{
PRELIMINARY PHYTOCHEMICAL ANALYSIS AND TOTAL PHENOL CONTENT OF ASHWAGANDHA (WITHANIA SOMNIFERA) EXTRACT
}

\author{
Harippriya Karthikeyan., Vishnupriya.V and Gayathri.R
}

Saveetha Dental College and Hospitals Chennai-77

Article History: Received $15^{\text {th }}$ December, 2016, Received in revised form $24^{\text {th }}$ January, 2017 Accepted $14^{\text {th }}$ February, 2017 , Published online $28^{\text {th }}$ March, 2017

Copyright $\odot 2017$ Harippriya Karthikeyan., Vishnupriya.V and Gayathri.R. This is an open access article distributed under the Creative Commons Attribution License, which permits unrestricted use, distribution, and reproduction in any medium, provided the original work is properly cited.

\section{INTRODUCTION}

Ashwagandha (Withania somnifera) also known as Winter cherry belongs to Solanaceae (Nightshade/Potato family). Withania somnifera is cultivated in many of the drier regions of India. It is also found in Nepal, China and Yemen. Nowadays it's being cultivated in some regions of South Africa and America, having mild climatic conditions. This herb is mostly used in Ayurvedic treatment and has its traditional roots of usage since then. The root of this plant is widely used for medicinal purposes. Not only roots, but its leaves and berries are also used for treating jaundice, by making decoction. This ancient Indian herbal plant has amazing healing properties that help us not only in treating various physical ailments but metal ailments such as stress, depression, restlessness, etc. Its medicinal properties are,

- Anti oxidative

- Anti bacterial

- Anti malarial

- Anti viral

- Anti cancerous

- Anti inflammatory

- Anti depressant

- Anti fertility

- Analgesic

- Cell rejuvenation

- Pain relieving

Ashwagandha is mostly used for treating patients having mental disorders such as stress, depression, etc. Thus it is widely used as as antidepressant. In ancient times, physicians recommended it to relieve muscular pains. Sometimes people use it for regulating anti fertility problems in men and women. Pregnant women are advised to take very minimal amount of withania somnifera as high dosages lead to damage of the foetus (ie. Teratogenecity)

*Corresponding author: Harippriya Karthikeyan Saveetha Dental College and Hospitals Chennai-77

\section{MATERIALS AND METHODS}

\section{Preparation of extract}

The Ashwagandha (Withania somnifera) root is collected, washed well and air dried. A few days later, the root sample is powder well and stored in polythene bag for use. An aqueous extract of ash was prepared and used for the further analysis. The Ashwagandha extract is prepared by taking the powdered root sample into a test tube and adding distilled water to it such that the plant powder is soaked in well and shaken well. The solution is then filtered by using a filter paper and the filtrate is collected in a separate test tube. This is filtered extract is used for further photochemical analysis.

\section{Phytochemical analysis}

Phytochemical analysis was done with reference to Abdul Wadood, Mehrene Ghufran and Syed Barbar et al (1000144)

\section{Test for Phlobatannins}

The extract is taken and distilled water is added to it. Shake it well. Now filter it to collect the plant extract. Then add $1 \%$ of aqueous $\mathrm{HCl}$ to the Ashwagandha extract and boil it with the help of hot plate stirrer. Brownish red precipitate is obtained. Red colour precipitation indicates positive result of Phlobatannins.

\section{COLOUR RATINGS: $4 / 5$}

\section{Test for Reducing Sugars}

The Ashwagandha extract is added to $5 \mathrm{ml}$ of distilled water. Then $1 \mathrm{ml}$ of ethanol is added and mixed. Next $1 \mathrm{ml}$ of Fehlings solution A and $1 \mathrm{ml}$ of Fehlings solution B are added in the test tube. Heat it till it boils and pour it in aqueous ethanol solution. Greenish brown precipitation is observed. Any change in precipitation's colour indicates positive result of Reducing sugars.

\section{COLOUR RATINGS: $3 / 5$}

\section{Test for Terpenoids}

The sample extract is added to $10 \mathrm{ml}$ of methanol. It is shaken well and filtered by using filter paper. This filtrate is collected and $2 \mathrm{ml}$ of chloroform is added. Now add $3 \mathrm{ml}$ of sulphuric 
acid to the Ashwagandha filtrate. Light brown precipitation is observed. Formation of reddish brown precipitation indicates positive test of Terpenoids.

\section{COLOUR RATINGS: $2 / 5$}

\section{Test for Flavonoids}

The Ashwagandha extract is taken. $10 \mathrm{ml}$ of distilled water, 5 $\mathrm{ml}$ of ammonium solution were added to a proportion of aqueous filtrate Ashwagandha extract, followed by the addition of $1 \mathrm{ml}$ of concentrated sulphuric acid. Brownish yellow coloured precipitation is observed. Yellow colour precipitate indicates presence of Flavanoids.

\section{COLOUR RATINGS: $1 / 5$}

\section{Test for Alkaloids}

Few amount of sample extract is taken and add $3 \mathrm{ml}$ of hexane to it. Mix it, shake it well and filter it. Pour $5 \mathrm{ml}$ of $\mathrm{HCl}$ it into the Ashwagandha filtrate containing hexane. Heat the mixture, filter it and add a few drops of picric acid to it. Light brown colour precipitation is observed. Formation of yellow colour precipitate indicates presence of Alkaloids.

\section{COLOUR RATINGS: $1 / 5$}

\section{Test for Total phenol}

The total phenol content of Ashwagandha is found by using Folin Ciocalteu's reagent and expressed in terms of Gallic acid equivalent. The total phenolic content can be calculated as natural compound (gallic acid) equivalent (GAE) by the following equation: $\mathrm{T}=\mathrm{C} \mathrm{XV} / \mathrm{M}$ where,

- $\mathrm{T}$ is the total phenolic content in mg.g-1 of the extracts as GAE,

- $\mathrm{C}$ is the concentration of gallic acid established from the calibration curve in $\mathrm{mg} \cdot \mathrm{ml}-1$

- $\quad \mathrm{V}$ is the volume of the extract solution in $\mathrm{ml}$ and $\mathrm{M}$ is the weight of the extract in $\mathrm{g}$.

Gallic acid is used as a standard compound and the total phenols were expressed as $\mathrm{mg} / \mathrm{g}$ gallic acid equivalent. The total phenolic content was found to be $70 \mathrm{mg} / 1 \mathrm{~g}$ of Gallic acid equivalent.

\section{RESULTS AND DISCUSSION}

This study has revealed that presence of phytochemicals as active medicinal chemical constituents. Important medicinal phytochemicals like Phlobatannins, Reducing sugars, Terpenoids, Flavanoids and Alkaloids were also found in the Ashwagandha extract.

\begin{tabular}{cc}
\hline TEST & RESULT \\
\hline Phlobatannins & ++++ \\
Reducing sugars & +++ \\
Terpenoids & ++ \\
Flavanoids & + \\
Alkaloids & + \\
\hline
\end{tabular}

From the results we have obtained, we can clearly see that Ashwagandha (Withania somnifera) is rich in Phlobatannins when compared to other important phytochemicals present in it. Phlobatannins have been reportedly known for their excellent wound healing properties that are anti inflammatory, analgesic and anti oxidative. Reducing sugars are the next most abundant phytochemicals found in Ashwagandha.

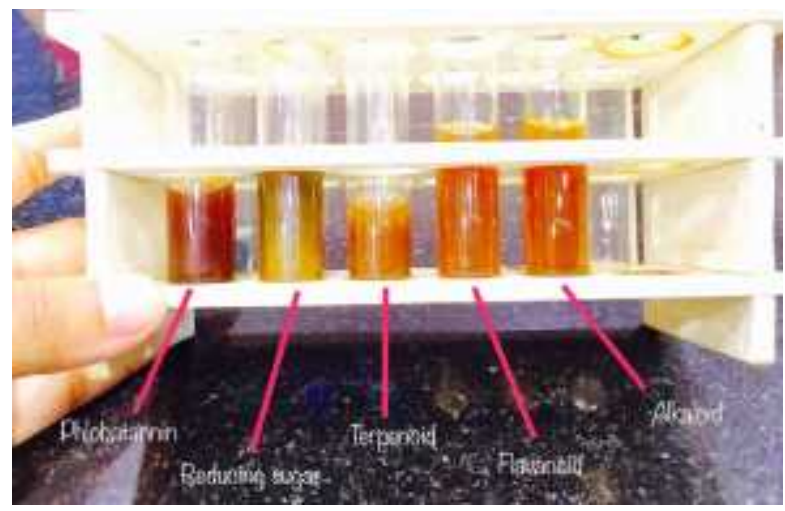

Since reducing sugars contain carbohydrates, glucose, etc we can also say that they play a vital role in controlling diabetes. Terpenoids are well known for their anti inflammatory, anti malarial, anti viral and anti bacterial properties. It is also very helpful in inhibition of cholesterol synthesis, thus helping in reducing fat depositions which in turn prevent heart related disorders and obesity. Flavanoids and Alkaloids are found in mild traces. Flavanoids greatly help out in preventing coronary diseases as per recent studies. Alkaloids are used for reducing headaches and fever. Thus we can also say that Alkaloids have analgesic and anti bacterial properties.

\section{CONCLUSION}

According to current studies we can say that Withania somnifera has many properties which help in the treatment of various human ailments. Widely well known for its healing properties to help in curing various psychological disorders like depression, mental illness, stress, insomnia, etc. From previous studies and our study, we have found out that this ancient Indian herb is rich in Phlobatannins. As we all know, Phlobatannins have high antioxidant properties that help in cell rejuvenation which in turn leads to better functioning of the organs and organ systems at cellular level. Thus we can say conclude that by using this amazing herb, we can heal nearly all ailments that are related physically and psychologically which will greatly help in benefiting not only that individual but also for the betterment of the society.

\section{References}

1. Narendra Singh, Mohit Bhalla and Marilena Gilca, An Overview on Ashwagandha: A Rasayana (Rejuvenator) of Ayurveda, African journal of traditional, complementary and alternative medicines

2. Morgan A. Pratte, Kaushal B. Nanavati and Christopher P. Morley, An Alternative Treatment for Anxiety: A Systematic Review of Human Trial Results Reported for the Ayurvedic Herb Ashwagandha (Withania somnifera) African journal of traditional, complementary and alternative medicines

3. Swati Dongre, Deepak Langade, and Sauvik Bhattacharyya, Efficacy and Safety of Ashwagandha (Withania somnifera) Root Extract in Improving Sexual Function in Women: A Pilot Study Asian journal of pharmaceutical and clinical research

4. Khan MA, Subramaneyaan M, Arora VK, Banerjee BD, Ahmed RS. Effect of Withania somnifera (Ashwagandha) root extract on amelioration of oxidative stress and autoantibodies production in 
collagen-induced arthritic rats Asian journal of pharmaceutical and clinical research

5. Franziska Spritzler, RD, CDE , 12 Proven Health Benefits of Ashwagandha Asian journal of pharmaceutical and clinical research

6. Mohammed Ziauddin Neeta Phansalkar Bhushan Patwardhan Studies on the immunomodulatory effects of Ashwagandha Asian journal of pharmaceutical and clinical research

7. K Chandrasekhar Department of Neuropsychiatry and Geriatric Psychiatry, Asha Hospital, Hyderabad, Andhra Pradesh, India, Jyoti Kapoor Ayurveda, Ashwins Health Care and Research Centre, Hyderabad, Andhra Pradesh, India, Sridhar Anishetty.

8. A prospective, randomized double-blind, placebocontrolled study of safety and efficacy of a highconcentration full-spectrum extract of Ashwagandha root in reducing stress and anxiety in adults, Indian journal of Psychological medicine
9. Anne McIntyre, An Overview on Ashwagandha: Winter Cherry - Withania Somnifera, Positive health medicinal works

10. Lakshmi-Chandra Mishra, MD (Ayur), PhD, Betsy B. Singh, PhD, Simon Dagenais, BA Scientific Basis for the Therapeutic Use of Withania somnifera (Ashwagandha): A Review, Pubmed

11. Sitanshu Kumar Verma and Ajay Kumar, Department of Biotechnology, Institute of Biomedical Education and Research, Mangalayatan University, Aligarh, UP, India, Indian journal of Psychological medicine

12. Therapeutic uses of Withania somnifera (ASHWAGANDHA) with a note on withanolides and its pharmacological actions., Asian journal of pharmaceutical and clinical research

13. N D Chaurasiya, Phytochemical analysis and variability preparation of Withania somnifera, Indian journal of Psychological medicine

\section{How to cite this article:}

Harippriya Karthikeyan., Vishnupriya.V and Gayathri.R (2017) 'Preliminary phytochemical analysis and total phenol content of Ashwagandha (withania somnifera) extract', International Journal of Current Advanced Research, 06(03), pp. $2856-2858$. DOI: http://dx.doi.org/10.24327/ijcar.2017.2858.0124 